\title{
Resumen de tesis: Itinerarios militantes entre dictaduras y conflictividad social. Del Partido Revolucionario de los Trabajadores al Partido Socialista de los Trabajadores (1965-1976)
}

\author{
Martín Mangiantini \\ (Universidad de Buenos Aires) \\ martinmangiantini@gmail.com
}

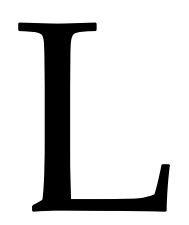

a investigación aborda la trayectoria de una corriente política que formó parte del amplio abanico de las izquierdas en Argentina, específicamente dentro del campo ideológico del trotskismo, entre los años 1965 y 1976. A lo largo de este período, la misma se manifestó a través de tres estructuras partidarias consecutivas: el Partido Revolucionario de los Trabajadores (PRT) desde su fundación en 1965 hasta su ruptura; el Partido Revolucionario de los Trabajadores-La Verdad (PRT-LV) entre 1968 y 1972 y, finalmente, el Partido Socialista de los Trabajadores (PST), desde su conformación hasta los inicios de la dictadura cívico-militar acaecida en 1976.

El análisis de este tipo de trayectorias militantes posibilita una profundización en torno a una serie de problemas sustantivos de la historia social y política argentina porque contribuye al estudio de las izquierdas y de las fuerzas políticas presentes desde mediados de los años sesenta hasta la antesala del golpe de Estado de 1976, en este caso, a partir del estudio de un objeto escasamente abordado en perspectiva historiográfica. Posibilita además reconstruir la relación entre esta corriente y el movimiento social en el que pugnó por influir, lo que permite complejizar el análisis de las heterogéneas organizaciones revolucionarias presentes en el período.

El trabajo parte de un balance en torno a la nutrida producción historiográfica que versa sobre la politización de esos años. En este, se visualiza una doble caracterización. En primer lugar, se da cuenta de una escasez de trabajos preocupados por indagar sobre la dinámica del movimiento social (la clase obrera o las juventudes, por ejemplo) en su relación con las organizaciones políticas revolucionarias que actuaron en su seno. Existe

\footnotetext{
${ }^{1}$ Tesis de Doctorado en Historia defendida el 29 de noviembre de 2017 en la Facultad de Filosofía y Letras de la Universidad de Buenos Aires. La investigación fue dirigida por el Dr. Hernán Camarero (CONICETUBA) y financiada por el CONICET (Beca de Culminación de Doctorado). Actuaron como jurados: Alejandro Schneider (UBA - UNLP), María Cristina Tortti (UNLP) y Vera Carnovale (UNSAM-CONICET). Calificación: Sobresaliente
} 
un importante cúmulo de aportes sobre el movimiento obrero, o bien, sobre diversos núcleos juveniles o sobre la intelectualidad; asimismo, se cuenta con una notoria producción con respecto a diversas organizaciones revolucionarias, pero, a la vez, se carece de estudios preocupados por una mayor conexión entre ambas esferas que den cuenta de la retroalimentación y diálogo entre ellas.

En segundo lugar, en lo pertinente al campo de las organizaciones revolucionarias propiamente dichas, se identifica una primacía por el estudio de aquellas propuestas político-militares (particularmente, el PRT-ERP) por sobre aquellas corrientes que, perteneciendo al campo de las izquierdas, no pusieron en práctica un aparato militar o brazo armado, sino que optaron por una estrategia de carácter insurreccional. Política Obrera, los partidos maoístas y la corriente aquí abordada son ejemplos de ello.

La tesis se estructuró en tres grandes bloques que permitieron brindar una mirada totalizadora del objeto a partir de un criterio de subdivisión no cronológico, sino temático, en el que cada capítulo remitió a una problemática en particular que se entrecruzaba con los restantes tópicos. En primer lugar, desde la historia de las ideas, se indagaron los posicionamientos de esta corriente ante los cambios políticos acaecidos entre 1965 y 1976, lo que permitió abordar los insumos teórico-conceptuales de los que se valió para pensar la coyuntura política y, por otro lado, reflexionar sobre las estrategias de intervención que se desprendieron de tales análisis. Por otra parte, se dio cuenta de los matices y divergencias presentes entre las diversas organizaciones revolucionarias como un modo de comprensión de las particularidades inherentes en el amplio espectro de las izquierdas.

En segundo lugar, se analizó esta experiencia desde el abordaje de su herramienta partidaria, lo que conllevó el estudio de diversas temáticas como, por ejemplo, la indagación en torno a los rasgos identitarios de su militancia. Inmiscuyéndose en el terreno de los imaginarios y las subjetividades, se intentó responder un interrogante: En un contexto de proliferación de organizaciones autoproclamadas revolucionarias, ¿qué características se vislumbraron como propias de esta corriente convirtiéndose en rasgos diferenciadores con respecto a otras propuestas de izquierda? En simultáneo, analizar la estructura organizativa implicó, por un lado, referirse a sus problemáticas y tensiones en el funcionamiento cotidiano (los liderazgos y personalismos o las tensiones entre sus distintos organismos, entre otros tópicos, forman parte de este desarrollo). Por otro lado, se analizó cómo esta organización se adaptó y reorientó a los cambios políticos acaecidos. Las problemáticas y tensiones surgidas en cuanto a las posibilidades de una militancia más expuesta o la necesidad de una práctica con lógicas de mayor resguardo y clandestinidad se transformaron en un denominador común.

Por último, en tercer lugar, se brindó centralidad al análisis sobre la inserción partidaria en el movimiento social y en su conflictividad, privilegiando el análisis sobre la presencia de esta corriente en la clase obrera y en sus organismos de representación gremial como así también en el repertorio de estrategias utilizado para lograr una mayor 
influencia. A la vez, se indagó sobre la política y presencia forjada en otros sujetos sociales como la juventud (en sus diversas expresiones), la militancia feminista y la intelectualidad, entre otros.

En la investigación tuvo un peso central una minuciosa indagación de la numerosa documentación interna elaborada por estas organizaciones. Más allá de la utilización de diversos insumos, se recurrió centralmente a los fondos documentales, escasos o nulamente explorados, que conforman el archivo de esta corriente. Se trata de un cúmulo de aproximadamente tres mil documentos internos relevados, mayoritariamente inéditos en las producciones preexistentes.

Si se valora el desarrollo de esta propuesta política exclusivamente desde sus aspectos cuantitativos, es factible concluir que se trató de una organización de limitado alcance en un marco en el que la idiosincrasia y el arraigo del peronismo fue mayoritario entre amplias capas de la población y que simultáneamente, dentro del nutrido abanico de las izquierdas, otras estructuras (por ejemplo, determinadas organizaciones político-militares o el Partido Comunista) gozaron de una militancia numéricamente más notoria. No obstante, extraer las conclusiones de las herramientas estadísticas daría como resultado una mirada parcial.

Se sostiene, como reflexión, que se trató de una corriente que expresó una impronta político-ideológica particular con desarrollo e inserción en el seno de ciertos núcleos de la clase obrera y de la juventud de los que, a su vez, se retroalimentó. En este sentido, la investigación ofrece diversos resultados.

Como primera conclusión, se esgrime que se trató de una propuesta con cierta presencia en aquellos sectores movilizados y radicalizados que formaban parte del entramado social como, por ejemplo, en el seno del movimiento obrero, entre la juventud y en diversas expresiones también activas como el movimiento por los derechos de las mujeres. A lo largo del trabajo, se dio cuenta de los ámbitos de implantación de estos grupos en el seno del movimiento obrero. La participación en los organismos gremiales del frigorífico Swift-Armour de Berisso o en los ingenios azucareros tucumanos en los años del PRT; la construcción de una tendencia dentro del gremio automotriz y el papel en la representación de los trabajadores del Banco Nación en el período del PRT - LV o la extensión de la presencia del PST en divergentes rubros y espacios laborales como los metalúrgicos, trabajadores de la construcción o docentes, permiten observar la vinculación establecida con el mundo de los trabajadores. Al mismo tiempo, la constante participación en la conflictividad fue otra expresión de una actividad política imbricada con la dinámica de los propios operarios. Por ello, se afirma que los partidos que representaron a esta corriente en los años sesenta y setenta fueron entidades que actuaron en el seno de la clase obrera y no como instancias ajenas a ella, siendo factible aseverar que la presencia de su militancia en el ambiente fabril y laboral se reveló como un elemento natural en la cotidianeidad y rutina de los trabajadores. 
De modo similar, esta premisa es pertinente para comprender la inserción en otros sujetos como es el caso de la juventud en la que esta corriente forjó cierta presencia, básicamente a través de la militancia universitaria. Si bien esta no se produjo sin ciertas tensiones, dadas las constantes directivas que reivindicaban la necesidad de proletarizar a la militancia estudiantil, la misma fue otro pilar del período. Espacios con presencia como la Facultad de Farmacia y Bioquímica de Buenos Aires, Arquitectura de La Plata y Córdoba o el Comedor universitario tucumano o rosarino, fueron expresiones de esta iniciativa que, a su vez, no descuidó otros ámbitos de confluencia juvenil como los colegios secundarios, los estudiantes extranjeros radicados en Argentina o los espacios de socialización barriales. Del mismo modo, la política desarrollada en los años setenta alrededor de problemáticas como la liberación de la mujer fueron facetas que refieren a una estructura que puso en práctica diversas iniciativas de inserción en el tejido social a través de una multiplicidad de temáticas e intentos de vinculación con sujetos potencialmente factibles de asimilar a una cultura política revolucionaria.

En la segunda conclusión se sostiene que, en un contexto de proliferación de organizaciones consideradas revolucionarias, esta propuesta tuvo diversas especificidades que significaron una novedad dentro del campo de las izquierdas argentinas y que imprimieron una impronta particular. En relación con ello, fue un rasgo distintivo el intento de vinculación con los trabajadores que adscribían al peronismo, ya sea, mediante la interpelación pública o, en oportunidades, a través de la confluencia con ellos en agrupaciones sindicales sosteniendo, al mismo tiempo, una delimitación teórico-ideológica. Independientemente del grado de éxito, se identifica que, ante la masividad del peronismo, la búsqueda de acercamiento a esta afiliación debía gestarse desde la comprensión del fenómeno y no desde una retórica impugnadora que impidiera forjar un diálogo con amplias franjas de la población representadas por su prédica. En simultáneo, los intentos de dotar a la clase obrera de una concepción y de un proyecto de pretensiones "internacionalistas" distinguieron a esta corriente de una cultura nacionalista en boga que la identidad peronista terminó de imprimir al mundo de los trabajadores como, así también, la diferenció de aquellas tesis emanadas del propio derrotero revolucionario de Rusia.

En tercer lugar, se concluyó que la oposición a la construcción de "ejércitos revolucionarios" o "focos armados" y la primacía por la inserción en el mundo fabril y sindical con la apelación a la movilización de los propios trabajadores se convirtió en un componente de peso de esta expresión en un contexto en el que, bajo la impronta aún presente de la Revolución Cubana y de teorías de ella desprendidas, fue notorio el desarrollo de organizaciones simultáneamente políticas y militares. Esta diferenciación no solo se manifestó desde un punto de vista teórico, sino también, al mismo tiempo, práctico. La búsqueda de inserción de una organización revolucionaria entre los trabajadores en el seno de los organismos de representación que estos forjaban, o bien, su intento de asimilación a las filas de una organización político-militar dejando en segundo plano la actividad 
militante en sus propios espacios laborales, fue también una discrepancia de peso manifestada en la práctica.

Estos intentos por no provocar un aislamiento de la organización política con respecto a los núcleos de trabajadores a los que se buscaba representar se vislumbró también en aquellas tentativas por aprovechar las instancias de participación electoral y la búsqueda de conformación de candidaturas y alternativas que pugnaran por articular la actividad sindical con la política. En un marco de primacía por el "abstencionismo" o el llamado al voto en blanco por parte de las izquierdas ello se convirtió en una particularidad de esta corriente sin que ello se transformara en una adopción de los antiguos paradigmas provenientes del ideario reformista. Reflejo de ello fue la participación electoral en las sendas elecciones acaecidas en el año 1973.

A la vez, la premisa que pugnó evitar la construcción de una herramienta política aislada del "movimiento de masas" se reveló como una característica de peso en los intentos por amoldar la estructura partidaria a los cambios coyunturales que acaecían y, sobre esa base, modificar con frecuencia la primacía por aquellas prácticas legales y expuestas por sobre la actividad clandestina, o viceversa. La mayor o menor utilización de los márgenes de acción posibles sobre la base de la caracterización en torno al grado de represión existente no siempre se desarrolló sin tensiones ni equívocos, encontrando álgidos momentos como, por ejemplo, en el bienio 1974-1975.

Por otro lado, es factible de mencionar la incorporación de temáticas soslayadas por las izquierdas argentinas en estos años. La propuesta programática y las iniciativas desarrolladas alrededor de la liberación de la mujer; el esbozo de reivindicaciones que impulsaban el respeto por la diversidad sexual; los replanteos y redefiniciones en cuanto al tipo de relaciones familiares y afectivas, entre otros ejemplos, imprimieron una marca identitaria particular que se halló en oposición tanto con el discurso expresado por el peronismo como por las organizaciones político-militares.

En perspectiva, más allá de la propuesta temporal del trabajo, es factible reflexionar que, una vez finalizado el proceso dictatorial en 1983, el trotskismo continuó su desarrollo con una mayor presencia en el movimiento obrero y la juventud. En relación con ello, resulta válido preguntarse si la experiencia de esta corriente en los convulsionados sesentas y setentas no significó un quiebre para forjar la implantación de esta tendencia dentro del movimiento social con una mayor consistencia que en los tiempos preexistentes y dar comienzo a un derrotero que hallaría continuidad y profundidad en las décadas posteriores.

Para citar este resumen:

Mangiantini, Martín (2018). Resumen de Tesis: Itinerarios militantes entre dictaduras y conflictividad social: del Partido Revolucionario de los Trabajadores al Partido Socialista de los Trabajadores (1965-1976). Anuario de la Escuela de Historia Virtual, 13, 125-129. 